\title{
Effect of Molecular Crowding on Conformation and Interactions of Single-Chain Nanoparticles
}

\section{Supporting Information}

Julian Oberdisse ${ }^{\mathrm{a}, \mathrm{b} *}$, Marina González-Burgos ${ }^{\mathrm{c}}$, Ander Mendia ${ }^{\mathrm{c}}$, Arantxa Arbe ${ }^{\mathrm{c} *}$, Angel J. Moreno $^{\mathrm{b}, \mathrm{c}}$, José A. Pomposo ${ }^{\mathrm{c}, \mathrm{d}, \mathrm{e}}$, Aurel Radulescu ${ }^{\mathrm{f}}$ and Juan Colmenero ${ }^{\mathrm{b}, \mathrm{c}, \mathrm{d}}$ ${ }^{a}$ Laboratoire Charles Coulomb (L2C), University of Montpellier, CNRS, 34095 Montpellier, France

${ }^{b}$ Donostia International Physics Center (DIPC), Paseo Manuel de Lardizabal 4, 20018 San Sebastián, Spain

${ }^{c}$ Materials Physics Center (MPC), Centro de Física de Materiales (CFM) (CSICUPV/EHU), Paseo Manuel de Lardizabal 5, 20018 San Sebastián, Spain

${ }^{d}$ Departamento de Física de Materiales, Universidad del País Vasco (UPV/EHU), Apartado 1072, 20080 San Sebastian, Spain

eIKERBASQUE - Basque Foundation for Science, María Díaz de Haro 3, 48013 Bilbao, Spain

${ }^{f}$ Forschungszentrum Jülich GmbH, Jülich Centre for Neutron Science JCNS at Heinz Maier-Leibnitz Zentrum MLZ, 85748 Garching, Germany.

* Authors for correspondence: julian.oberdisse@ umontpellier.fr; a.arbe@ehu.eus 


\section{Kinetics of SCNP-aggregation:}

We monitored by DLS the aggregation of PS-SCNPs in solutions at two different concentrations $(1 \mathrm{mg} / \mathrm{mL}$ and $2 \mathrm{mg} / \mathrm{mL}$ ) in DMF. Following the procedure described in the manuscript (see synthesis of SCNPs section), two samples were prepared.

The copolymerization of $\mathrm{S}(2 \mathrm{ml}, 17.5 \mathrm{mmol})$ and CMS $(0.615 \mathrm{ml}, 4.4 \mathrm{mmol})$ was carried out using ACVA (1.4 mg, 4.98 $\left.\times 10^{-3} \mathrm{mmol}\right)$ as initiator. The reaction mixture was degassed by passing argon for $15 \mathrm{~min}$ and then stirred for $3 \mathrm{~h}$ at $80{ }^{\circ} \mathrm{C}$. After that, the copolymer was redissolved in a minimal amount of THF and added to a large excess of methanol. The resulting precursor was isolated by filtration and further dried at r.t. under vacuum (Yield: $20 \%, \mathrm{M}_{\mathrm{w}}$ $\left.(\mathrm{SEC})=269 \mathrm{~kg} / \mathrm{mol}, \mathrm{M}_{\mathrm{w}} / \mathrm{M}_{\mathrm{n}}=1.485\right)$.

Poly(styrene-co-chloromethyl styrene) (200 mg, $1.65 \mathrm{mmol})$ was dissolved in DMF (8 ml) at room temperature. Then, $\mathrm{NaN}_{3}$ (2eq., $67.1 \mathrm{mg}, 10.32 \mathrm{mmol}$,) was added and the mixture was maintained under stirring for $24 \mathrm{~h}$. After reaction completion, the system was concentrated and precipitated in a mixture of $\mathrm{MeOH} / \mathrm{H}_{2} \mathrm{O}(1: 1)$. Finally, the resulting precursor was dried in a vacuum oven at room temperature (Yield: $79 \%, \mathrm{M}_{\mathrm{w}}(\mathrm{SEC})=315 \mathrm{~kg} / \mathrm{mol}, \mathrm{M}_{\mathrm{w}} / \mathrm{M}_{\mathrm{n}}=1.462$ ).

Poly(S-co-AMS) copolymer precursor $(100 \mathrm{mg}, 0.84 \mathrm{mmol})$ was dissolved in DMF (100 ml) at room temperature. Then, the mixture was heated to $200{ }^{\circ} \mathrm{C}$ under microwave irradiation $(300$ $\mathrm{W}, 150 \mathrm{psi}$ ) and maintained there for $30 \mathrm{~min}$. The system was cooled down to room temperature and concentrated in a vacuum line using Schlenk flasks. The sample has been named SCNPs_1mgmL.

Starting from the same precursor a synthesis at $2 \mathrm{mg} / \mathrm{ml}$ (50mg precursor in $25 \mathrm{ml} \mathrm{DMF}$ ) was carried out. The same steps described above have been carried out. The sample has been named SCNPs_2mgmL.

The hydrodynamic radius $\left(R_{H}\right)$ of the nanoparticles has been obtained from dynamic light scattering (DLS) measurements on the solutions of samples SCNPs_1mgmL and SCNPs_ $\mathbf{2 m g m L}$ at 1 and $2 \mathrm{mg} / \mathrm{mL}$ respectively. It has been used the DLS ZetaSizer $(\lambda=633 \mathrm{~nm})$. A CONTIN fit has been made on the average obtained from 6 measurements (see figures 1 and 2) at a scattering angle of $173^{\circ}$.

As can be seen in Figures S1 and S2, the nanoparticles freshly synthesized at the two concentrations show a very similar distribution of sizes. Those obtained at $1 \mathrm{mg} / \mathrm{mL}$ do not show aggregation symptoms after almost 3 months. Nanoparticles synthesized at $2 \mathrm{mg} / \mathrm{mL}$, however, seem to start aggregating after about 15 days. 
SSCNPs_1mgml
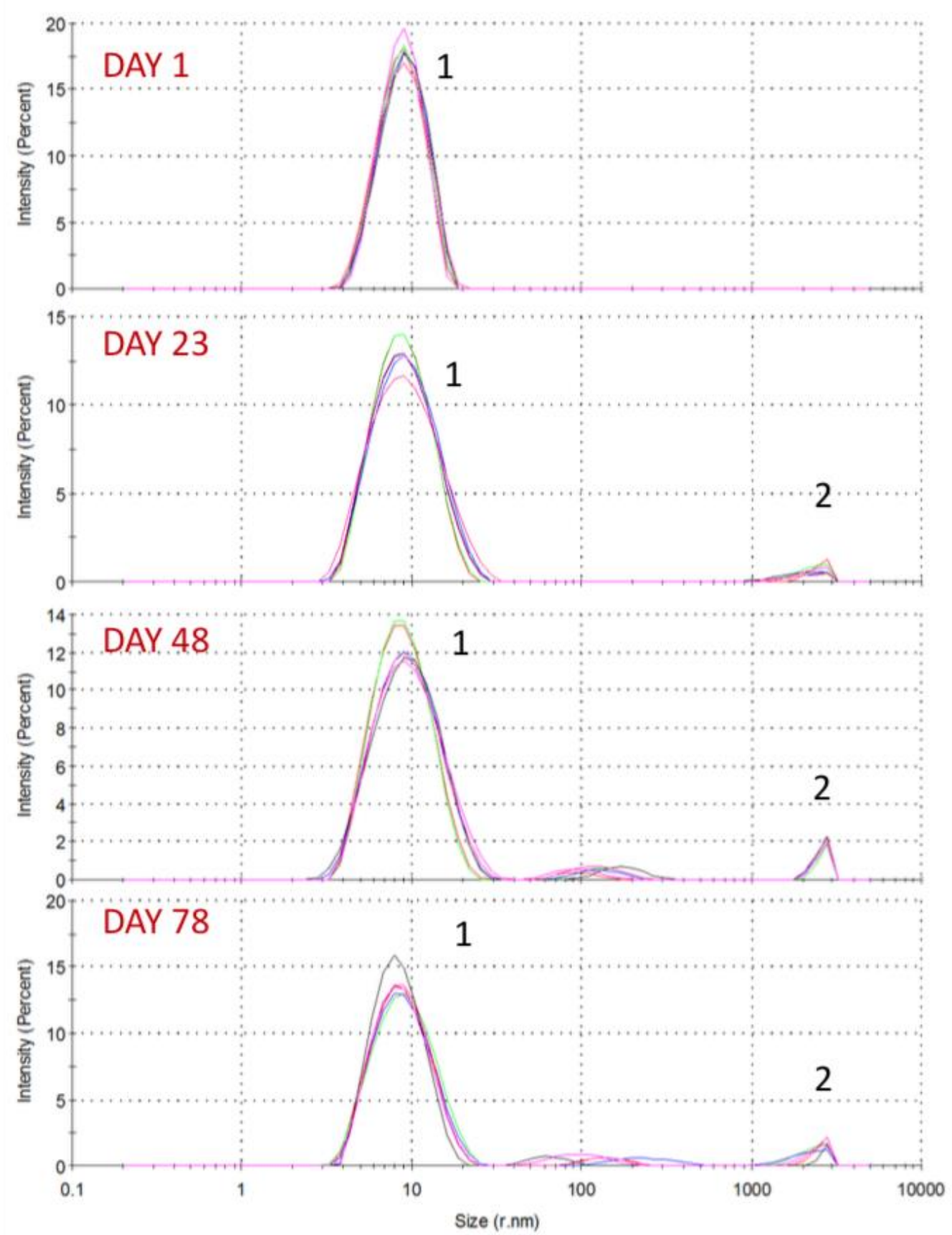

\begin{tabular}{|c|c|c|}
\hline DAY & PEAK 1/ r $(\mathbf{n m})$ & PEAK 2 / r $(\mathbf{n m})$ \\
\hline 1 & 9.03 & - \\
\hline 23 & 9.29 & 2508 \\
\hline 48 & 9.32 & 2654 \\
\hline 78 & 9.20 & 2403 \\
\hline
\end{tabular}

Figure S1: Evolution of SSCNPs_1mgmL for 78 days 
SSCNPs_2mgml
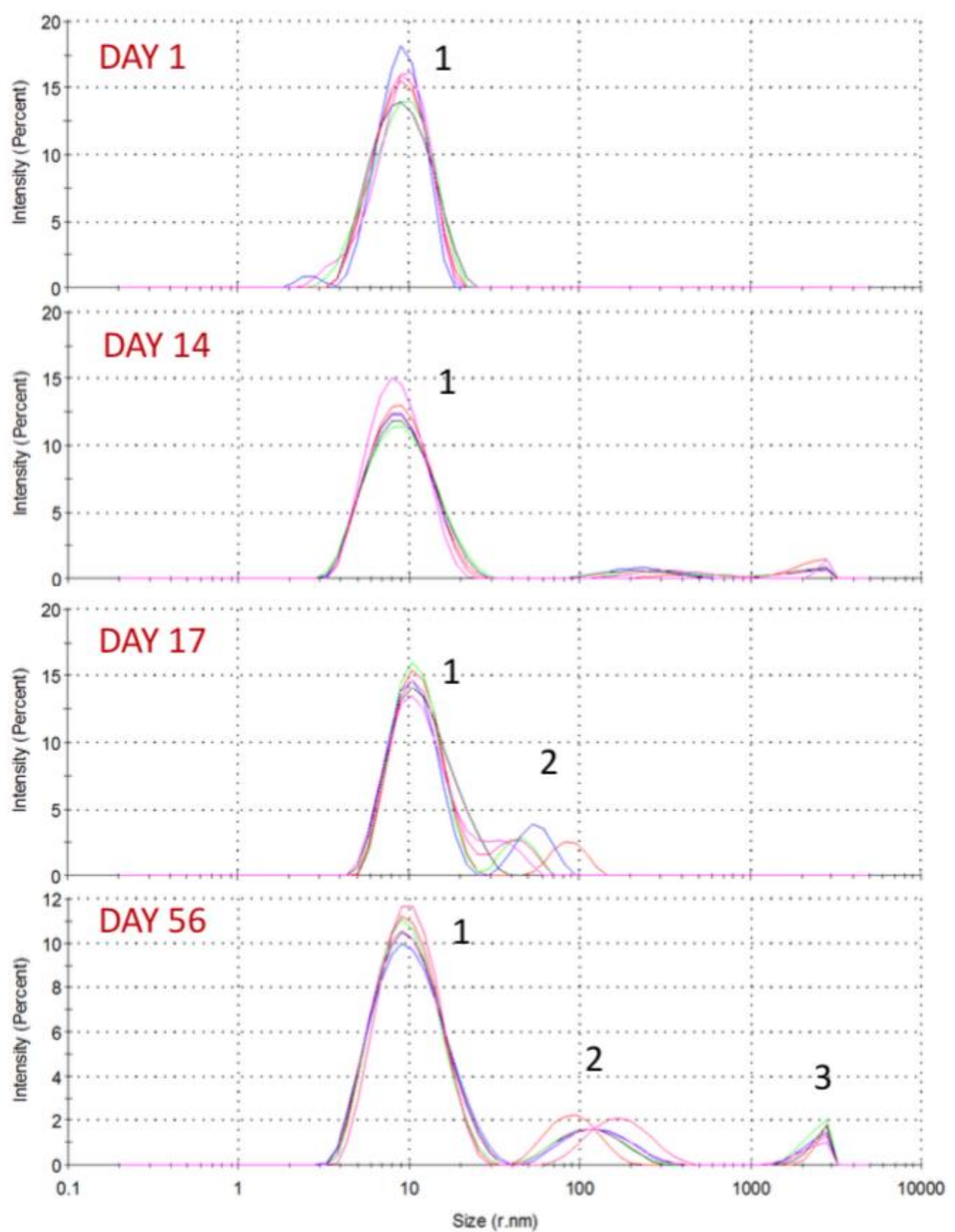

\begin{tabular}{|c|c|c|c|}
\hline DAY & PEAK 1/r (nm) & PEAK 2 / r (nm) & PEAK 3 / r (nm) \\
\hline 1 & 9.45 & - & - \\
\hline 14 & 9.33 & - & - \\
\hline 17 & 11.60 & 87.61 & - \\
\hline 56 & 11.12 & 93.27 & 2289 \\
\hline
\end{tabular}

Figure S2: Evolution of SSCNPs_2mgmL for 56 days. 